\title{
Measuring College Students' Motivation: Validity Evidence for the MUSIC Model of Academic Motivation Inventory
}

\author{
Ming Li \\ School of Foreign Languages \\ Shanghai University of Engineering Science \\ bahalucy@163.com
}

\begin{abstract}
The purpose of this study is to examine the psychometric properties of the college-level MUSIC model of motivation inventory. Three approaches were used to test the inventory, the internal consistency reliability, the fit index and factor loadings, and the correlation between the five scales in the MUSIC model inventory and student engagement. The results showed that this inventory demonstrates acceptable psychometric properties for use with college students. Therefore, College professors can use the MUSIC model inventory to assess students' motivation-related course perceptions in order to improve their teaching capabilities and overall professional development.
\end{abstract}

Keywords-the MUSIC Model of Motivation inventory; motivation; engagement; assessment

\section{INTRODUCTION}

In the past few decades, the quality of college instruction has obtained more and more attention in the reform of higher education. Therefore, to find a set of the suitable instrument to examine students' course perceptions in order to guide teachers' instructional capability is urgent and crucial to the higher education reform. In the realm of educational psychology, there are many instructors and researchers focusing on the research of motivation, that is, how to motivate students to engage in their learning. As a result, there appeared a lot of theories concerning motivation research such as the self-decide theory, the self-efficacy theory, the self-concept theory, expectancy-value theory and the attachment theory. For the instructors outside the realm of educational psychology, these theories are hard to understand and be practiced for these instructors. Therefore, Jones, a motivation scientist in the U.S., synthesized these theories and research into a model, called the MUSIC Model of motivation and he also designed an instrument to examine students' course perceptions called the MUSIC model inventory[1]. Dr. Jones holds that instructors should always think about their instructional design from the following five aspects: Teachers should consider if the students feel that they are empowered in class and that the content of the course is useful for their short- and long-term future. Also, teachers should put students' sense of success, interest, and sense of caring into consideration if they want to motivate students to engage in learning.

The MUSIC Model of motivation and the relevant inventory have been used in many countries and they have been proved to be effective tools for teachers' professional development both in the U.S. and other countries [2-7]. The new national standard of college teaching calls for high-quality teaching among college professors. However, it is hard to find a suitable instrument to examine whether the professors' instruction has been improved or not since the use of some new teaching methods. Therefore, we try to use the MUSIC model of motivation inventory to measure Chinese college students' course perceptions. If it works well and has acceptable reliability and validity, it will benefit more and more teachers and college students in the future.

\section{Purpose AND ResEARCH Questions}

The purpose of this study is to test the reliability and validity of the college-level MUSIC model of motivation inventory. As a result, the research question is, to what extent the MUSIC model inventory produces valid scores when it is used with the college-level students?

\section{Procedure ANd Methods}

\section{A. Participants and Process}

Participants were 860 college students from a university enrolling in more than twenty different courses. The author translated the original English version of the inventory into Chinese according to the standard return translation process [8]. Before handing out the questionnaires, the investigators first state the purpose, emphasize that only those who agree to join the investigation would stay and answer the questionnaire. In terms of the participants' information, $97 \%$ of them claim that they are Han nationality and three percent claim that they are ethnic minorities. The average age of the participants is 21 .

\section{B. Instruments}

There are 26 items in the college-level MUSIC Model Inventory and they are grouped into five scales such as empowerment, usefulness, success, interest, and caring. The scales of empowerment and usefulness include five items respectively; the scale of success includes four items, and the scales of interest and caring include six items respectively. The response options for each item are as follows: $1=$ strongly disagree, 2 = disagree, $3=$ disagree, $4=$ agree, $5=$ agree, $6=$ strongly agree. The average score of the items on each scale is the final mean score of the scale. Researchers found that for different types of students in different countries, the reliability 
and validity of the MUSIC model inventory was acceptable. ([4][9-10])

\section{Engagement}

To measure students' engagement, we selected a four-item effort scale to evaluate the student's effort. The scale is also based on the Likert 6-point scale: 1 = strongly disagree, 2 = disagree, $3=$ somewhat disagree, $4=$ somewhat agree, $5=$ agree, $6=$ strongly agree. Here's an example: "I put a lot of effort into this course." Previous studies have found that this effort scale has good reliability [5].

\section{Data Analysis}

We used SPSS(version 24.0) for the Analysis and interpretation of the data. We tested the internal consistency reliability for all the 26 items in the MUSIC Model inventory, the four items of the course effort, and one item of the overall course perception by calculating the Cronbach's alpha values. The criteria are provided by Kline [11]: the alpha value greater than 0.9 is excellent, the value between 0.7 to 0.9 is good, the value between 0.6 and 0.7 is acceptable, and the value less than 0.6 is considered unacceptable. In order to test the fit of the 26 items in the MUSIC model inventory with the five factors in the MUSIC model, we used AMOS (version 22.0) to conduct the Confirmatory factor analysis(CFA). We used three fit indices to test the results of the CFA, namely, comparative fit index (CFI), the standardized root mean square residual (SRMR), and the root means the square error of approximation(RMSEA). We calculated the Pearson correlation coefficients between the various variables in the MUSIC model inventory and expected to achieve the appropriate correlation, as in previous studies[5].

We then calculate the factor loading to see if the loading of each item on the corresponding factor meets our expectations, which is acceptable if the loading value of each item is greater than 0.32 [12]. To provide evidence of the predictive validity of the MUSIC inventory, we used SPSS (version 22.0) software to calculate the Pearson correlation coefficient between the five scales in the MUSIC inventory and the course effort. Because the previous studies have indicated that students' course perceptions can predict their engagement[5], we predict that the five scales in the MUSIC inventory will be positively correlated with students' self-report effort. We use the correlation coefficient criteria of Cohen [13].

\section{E. The Results of the Study}

We use the Cronbach's Alpha value to assess the reliability of each scale in the MUSIC model inventory, with alpha values ranging from 0.81 to 0.89 (see Table I). Therefore, we consider that the reliability of each scale in the MUSIC inventory is good [11].

TABLE I.

CRONBACH’S ALPHA VALUES AND FIT INDICES

\begin{tabular}{|c|c|c|c|c|c|c|c|}
\hline & Cronbach's & alpha & valu & & & & \\
\hline $\mathrm{M}$ & $\mathrm{U}$ & $\mathrm{S}$ & $\mathrm{I}$ & $\mathrm{C}$ & CFI & SRMR & RMSEA \\
\hline .81 & .83 & .82 & .89 & 81 & 0.90 & 0.07 & 0.065 \\
\hline
\end{tabular}

We carefully analyze the correlation between the five scales in the inventory and between them and student effort. The results show that the coefficients range from 0.34 to 0.69 (see Table II) between the five scales in the MUSIC inventory. The data in Table I show that the fit index values of the 26 items in the inventory are acceptable or good with the MUSIC model. CFI values indicate that the fit is acceptable, SRMR values indicate a good fit, and RMSEA values indicate a good fit [14].

Table III is the standardized factor loadings of the MUSIC inventory, with loading values ranging from 0.51 to 0.84 , indicating that the 26 items have very good loadings on the five factors in MUSIC model [12].

In order to test the predictive validity of the five scales in the MUSIC inventory, we calculated the correlation coefficients between the five scales in the MUSIC inventory and the student effort.

The correlation coefficients between the five scales and student effort, and the overall course rating are moderate, ranging from 0.39 to 0.60 (see Table II).

TABLE II. PEARSON'S CORRELATION COEFFICIENTS FOR THE STUDY VARIABLES

\begin{tabular}{|c|c|c|c|c|c|c|}
\hline \multirow{2}{*}{$\frac{\text { Variables }}{1 . \text { Empower }}$} & 1 & 2 & 3 & 4 & 5 & 6 \\
\hline & & & & & & \\
\hline 2. Usefulness & $.43^{* *}$ & & & & & \\
\hline 3. Success & $.69^{* *}$ & $.48^{* *}$ & & & & \\
\hline 4. Interest & $.65^{* *}$ & $.57^{* *}$ & $.62^{* *}$ & & & \\
\hline 5. Caring & $.55^{* *}$ & $.47^{* *}$ & $.34^{* *}$ & $.56^{* *}$ & & \\
\hline 6. Effort & $.53^{* *}$ & $.46^{* *}$ & $.48^{* *}$ & $.60^{* *}$ & $.39^{* *}$ & \\
\hline
\end{tabular}

TABLE III. STANDARDIZED FACTOR LOADINGS FROM THE CFA

\begin{tabular}{|c|c|c|c|c|c|}
\hline Item & Empowerment & Usefulness & Success & Interest & Caring \\
\hline M1 & .63 & & & & \\
\hline M2 & .51 & & & & \\
\hline M3 & .52 & & & & \\
\hline M4 & .77 & & & & \\
\hline M5 & .62 & & & & \\
\hline U1 & & .75 & & & \\
\hline U2 & & .68 & & & \\
\hline U3 & & .70 & & & \\
\hline U4 & & .73 & & & \\
\hline U5 & & .72 & & & \\
\hline S1 & & & .72 & & \\
\hline S2 & & & .76 & & \\
\hline S3 & & & .71 & & \\
\hline S4 & & & .78 & & \\
\hline I1 & & & & .80 & \\
\hline $\mathrm{I} 2$ & & & & .83 & \\
\hline I3 & & & & .84 & \\
\hline I4 & & & & .82 & \\
\hline I5 & & & & .76 & \\
\hline I6 & & & & .80 & \\
\hline C1 & & & & & .59 \\
\hline $\mathrm{C} 2$ & & & & & .71 \\
\hline C3 & & & & & .72 \\
\hline C4 & & & & & .75 \\
\hline C5 & & & & & .67 \\
\hline C6 & & & & & .78 \\
\hline
\end{tabular}


students' motivation in engineering capstone courses. Interdisciplinary Journal of Problem-based Learning, 7(2), 34-71, 2013.

The purpose of this study is to test the reliability and validity of the college-level MUSIC model of motivation inventory. First, the internal consistency reliabilities are tested by using the Cronbach's alpha value in the MUSIC model inventory, and secondly, the fit index and factor loadings are calculated through the confirmatory factor analysis (CFA) to test its construct validity. Finally, the predictive validity of the MUSIC inventory is tested by calculating the correlation coefficient between the five scales in the MUSIC model inventory and student effort. The results of the above-mentioned studies provide relevant evidence for the validity of the MUSIC model of motivation inventory.

\section{ACKNOWLEDGMENT}

This paper was part of the achievement of the project entitled the Instructional reform for college-level English classes based on the national college education reform from the motivation perspective, and it was supported by Shanghai Foreign Language Education Press and China's Foreign Language Textbooks and Pedagogy Research Center with the grant No. 2018SH0037A. This paper was also part of the achievement of the project entitled First-class Discipline Construction of Foreign Language and literature and it was supported by Shanghai University of Engineering Science with grant No. 2019XKZX011.

\section{REFERENCES}

[1] Jones, B. D. Motivating Students to Engage in Learning: The MUSIC Model of Academic Motivation. International Journal of Teaching and Learning in Higher Education, 21(2), 272-285, 2009.

[2] Jones, B. D., Epler, C. M., Mokri, P., Bryant, L. H., \& Paretti, M. C. The effects of a collaborative problem-based learning experience on
[3] Jones, B. D., Tendhar, C., \& Paretti, M. C. The Effects of Students' Course Perceptions on Their Domain Identification, Motivational Beliefs, and Goals. Journal of Career Development, 43(5), 383-397, 2 016.

[4] Jones, B. D., Byrnes, M. K., \& Jones, M. W. Validation of the MUSIC Model of Academic Motivation Inventory: Evidence for Use with Veterinary Medicine Students. Frontiers in Veterinary Science, 6: 1-9, 2019. doi:10.3389/fvets.2019.00011

[5] Li, M., Wang, S.Examining the relationships between college students academic motivation, engagement and achievement under the guidance of the national standard of college education quality, Overseas English, 6:9-12, 2019.(In Chinese)

[6] Li M. Examining English majors academic motivation based on the motivational strategies Overseas English, 7:5-7, 2019.(In Chinese)

[7] Li, M., Yu, L., Qin Y., Lu, P., \& Zhang, X. College student academic motivation and engagement in the College English course. Theory \& Practice in Language Studies, 6(9), 1767-1773, 2016.

[8] Villagran, M. M., \& Lucke, J. F. Translating communication measures for use in non-English-speaking populations. Communication Research Reports, 22(3), 247-251, 2005.

[9] Li, M., Zhao, G., \& Cao, G. A survey report of Chinese college students' perceptions of the College English course. Theory \& Practice in Language Studies, 6(8), 1557-1565, 2016.

[10] Jones, B. D., \& Skaggs, G. E. Measuring students' motivation: Validity evidence for the MUSIC Model of Academic Motivation Inventory. International Journal for the Scholarship of Teaching and Learning, 10(1), 2016. doi:10.20429/ijsotl.2016.100107

[11] Kline RB. Principles and Practice of Structural Equation Modeling. New York, NY: Guilford Press, 2005.

[12] Tabachnick BG, Fidell LS. Using Multivariate Statistics, 3rd ed. New York, NY: Harper Collins, 1996.

[13] Cohen J. Statistical Power Analysis for the Behavioral Sciences, 2nd ed. Hillsdale, NJ: Erlbaum, 1988.

[14] Hu LT, Bentler PM. Cutoff criteria for fit indices in covariance structure analysis: conventional criteria versus new alternatives. Struct Equ Model. 6 (1):1-55,1999. 